die angenommene Entslehungsweise die richtige sey, da sie sich hei einer so grolsen Anzahl von Körpern nach den einfachsten Gesetzen wiederholt und der Einwurf einer zufälligen Uebereinstimmung durch die grofse Anzahl von Analogien gänzlicl boseitigt wird.

Auch zeigt die allmälige Abscheidung von krystallisirten Körpern aus den ätherischen Oelen, wenn letztere längere Zeit sich selbst überlassen bleiben, deullich genug, dafs ganz ähnliche Processe nach der 'Trennung der ätherischen Oele von den Pflanzen vor sich gehen, indem die Stearoptene meist Hydrüre oder Oxyde der ätherischen Oele sind, und es wohl kaum zweifelhaft ist, dafs diese Körper zum Theil erst einer Melamorphose der Oele ihren Ursprung verdanken.

Es scheint, dafs dic Stearoptene Zwischenstufen zwischen den Oelén und den Harzen darstellen, und dafs ilire Entstehungswoise in einigen Fällen (wie aus dem Geselz V. hervorgeht) sogar mil der Entstehungsweise der Harze zusammenfallt.

\title{
Ueber die Milchsäure und ihre Salze;
} von II. Engelhardl und R. Maddrell.

Dafs die Milchsäure in verschiedenen thierischen Flüssigkeiten, namentlich der des Muskelfleisches, vorkommt, hat Hr. Prof. v. Liebig durch scine neuesten Forschungen und Untersuchungen dargethan und so die Angaben von Berzelius bestätigt; dafs sie höchst wichtige Funclionen in thierischen Organismus zu erfüllen hat, gciit daraus zur Evidenz hervor. 
Dieser Umstand, der uns eine gründliche, au gedehnte Kenntnifs der Milchsäure, besonders ilırer Salze, sehr bedeutsam erscheinen liels, verbunden mil einer Aufforderung des Hrn. Prof. v. Li ebig, diesen Stoff zum Gegensland einer speciellen Untersuchung zu wälslen, waren die nächste Verlassung zu vorliegender Arbeit, bei deren Ausführung wir uns stets des gütigen Raths und der Mitwirkung unseres luochverehrten Lehrers zu erfreuen hallen. Die Resultate der Unlersuchung stimmen im Allgemeinen mil den Früheren überein, zeigen jedoch, namentlich in Bezug auf den Wassergeltalt der Salze, einige Abweichungen; auch glauben wir unsere Mühe durch Auffindung mehrerer neuen und interessanten Verhältnisse uuf's Schönste belohnt ru sehen.

Es schien uns vor Allem wünschenswerth und von hoher Wichtigkeit, cine characterische Reaction der Milchsâure zur Nachweisung geringer Quantiläten zu erhalten, da wir in Beziehung auf die von Pelouze*) angegebene ganz dasselbe gefunden haben, was Strecker**) hierüber publicirt hat. Wir müssen jedoch mit Bcdauern gestehen, dafs es uns nicht gelungen, der Wissenschaft hierin einen Dienst zu leisten, und dafs man nur durch die Analyse eines Salzes sich über das Vorhandenseyn der Mlilchsäure Aufschlufs verschaffen kann.

Wir wählten zur Darstellung der Milchsäure die von Bensch ***) angegeliene Hethode und erhielten aus 18 Pfund Rohrzucker elwa 21 Pfund milchsauren Kalk; die Theorie verlangt bei der Annahme, dafs aus dem Rohrzucker durch die Gährung nur Milchsäure hervorgehe, 31 Pfund. Wendet man statt braunen, weifsen Zucker an, so bekommt man bei der ersten

*) Diese Aunal. Bd. LIII S. 124.

**) Ebendaseltist Bd. LXI S. 216.

$* *$ ) Ehendasellist Bd. IXI S. 174. 
Krystallisation ein vollkommen weifses Product und ist so der unangenehmen und Verlust nach sich ziehenden Operation des mehrmaligen Auspressens, was eben keinen anderen Zweck hat, als den braumen Farlsstoff zu entfernen, überhoben. Die aus dem Zinksalz durch Schwefelwasserstof abgeschicdene Säure wurde zur Syrupsconsistenz eingedampft, und in Aelher, in welchem sie in jedem Verhältnif's löslich, aufgenommen, wo alle Verunreinigungen zurückblieben und durch Abdestilliren des Aethers, der sich zu wiederholten Malen verwenden läfst, vollkommen rein erhalten. Der geringe in Aether unlösliche Theil bestand aus milchsaurer Bitter- und Kalkerde, von welchen Basen man das kohlensaure Zinkoxyd, welches zur Sätligung der Milchsäure diente, nur schwierig befreien kann. Durch Umbrystallisiren das milchsaure Zinkoxyd absolut zu reinigen, gelang uns nicht, wenigstens vermochten wir die Bittererde nicht davon zu trennen, und es dürfte das Verhalten durch die nahe gleiche Löslichkeit und den allem Anschein nach Statl findenden Isomorphisnus der beiden Salze eine Erklärung finden. Da, wie erwähnt, die Milchsäure stets, um sie rein zu crhalten, in Aelher gelöst werden mufs, so kann man sich mit vielem Vortheil und Zeitersparnifs zur Reindarstellung dersellen auch des, durch mehrmaliges Umkrystallisiren von aller stickstofflialtigen Substanz, die ihm mit grofser Neigung folgt, befreiten Kalksalzes bedienen. Man löst zu diesem Zweck das Salz in so wenig als möglich Wasser, setzt cine zur Zersetzung genau berechncte Menge reiner Schwefelsäurc hinza und fält den gebilduten Gyps durch Alkohol, filtrirt nach dem Erwärnen und vollständigcm Absalz des Gypses und wäscht letztern mit verdümitem Alkohol aus. Hat man dafür Sorge getragren, dal's Schwefelsäure nicht im Ueberschufs angewandt wurde, sondern ein geringer Theil des Kalksalzes unzersetzt blieb, so läfst sich nach dem Eindampfen zum Syrup und Aufnahme in Aether, die Hilchsäure elsenfalls absolut rein crhalten. 
Bei zwei verschiedenen Productionen des Kalksalzes, bei welchen ganz auf dieselbe Weise, nur mit dem Unterschied, dafs eine Portion mehrere Tage länger der Einwirkung der Wärıne ansgesetzt gewesen, verfahren worden war, bekamen wir in dieser letzteren eine ziemlich beträchtliche Menge Bultersäure, während die andere keine Spur entlielt; ein Argument, dafs die Milchsäurebildung der Buttersäurebildung stets vorangeht. Die Beobachlung Wackenroder's*), dafs bei der Darslellung der Milchsäure durch Anwendung eines fetlfreien Ferments keine Bultersäure gebildet worden war, dürfte durch dieses Aufeinander - und nicht Nebeneinandergehen der beiden Säurcbildungsprocesse eine befriedigendere Erklärung fiuden, als durch dic Aunahme, dafs das Fett dic Entstehung der Butlersäure bedinge. Direcle Versuche haben diese Vermulhungs vollkommen bestätigt, denn wendet man durch Sättigen des kohlensauren Kalks mil reiuer Milchsäure erhaltenen milchsauren Kalk an und bedient sich des fettfreien Caseüns als Ferment, so trilt, führt man die übrigen zur Bultersäurebildung erforderlichen bedingungen herbei, diese sehr bald ein. Ferner der Umstand, dafs der zweimal umbrysiallisirle, also wohl fetl-, aber noch nicht slicksloffreie, rohe, milchsaure lialk zur Buttersäuregährung noch ausgezeichnet fähig ist, solite wohl iber diese Frage keinen Zweifel lassen. Es ist auffallend, welche geringe Menge stickstoffhaitiger Materie im milchsauren lialk denselben noch gährungsfähig macht, und drängte sich uns die Vermulhung auf, dafs das vollkommen reine Kalksalz ohne Gälırungsmiltel sogar dic Eigenschaft besitzen könne, in bultersauren lialk überzugehen. Wir stellten. in dieser Richtung einen Versuch an und exponirten das Salz sechs Wochen einer Temperatur von $30^{\circ}$, aber nicht eine Spur Bultersäure war nachzuweisen; es hatte sich unverändert erhallen. Zur Untersuchung der bei der

*) Arch. d. Pharm. Bd. XILVII 2. R. S. 259. 
Buttersäuregährung auftretenden Gase, sowie zur Erledigung der Frage, ob vielleicht die Bildung der Buttersäure aus Milchsäure an den Zutrilt der Luft geknüpft sey, wurde eine Portion des rohen Kalksalzes mit Caseïn versclzt und in einer Flasche, welche mit einem Ablcitungsrohr versehen war, der Temperatur von $30^{\circ}$ längere Zeit ausgesetzt. Die rasche Gasentwickelung ergab bald, dafs die Luft zur Bildung der Buttersäure nicht nölhig, doch war die Gährung in einem offenen Gefüfs mil derselben Quantität angestellt eher beendigt, als die in dem verschlossenen, so dafs also der Zutritt der Luft auf die Gährung beschleunigend einzuwirken scheint. Eine Untersuchung der Gase ergab, entsprechend der Theorie, das Verhältnifs von Kohlensäure und Wasserstoffyas circa wie $3: 4$.

- Bei der Milchsäurebereitung aus Zucker soll neben derselben noch Mannit und ein gummiartiger Körper entslehen. Letzteren haben wir ebenfalls beobachtet, doch ersteren auf keine Weise nachzuweisen vermocht.

Dampft man die Multerlange bis zur Syrupdicke cin und behandelt sie mit gewöhnlichen kochendem Weingeist, so lüst dieser einen grofsen Theil des Syrups auf und es scheiden sich beim Erkalten beträchlliche Quantitäten cincr krystallinischen Massc aus. Sie enthält eine Kalkverbindung. In Wasser gelöst, durch kohlensaures Ammoniak gefält und stark eingedampft, zeigt der erhaltene Syrup nicht den geringsten süfsen Gesclimack; es war also kein Mannil vorhanden. Bei diesen Versuchen stielsen wir auf eine eigenthümliche Kalkverbindung. Die aus der weingeistigen Lösung erhaltenen Krystallmassen, die, wie erwälınt, keinen Mannit enthielten, wurden durch melirmatiges Umkrystallisiren aus gewöhnlichem Weingeist gereinigt und zuletzt mit kochendem absolutem Alkohol behandelt, worin sie sich leicht auflösen; ein Kriterium von milchsaurem Kaik, welcher darin beinahe unlöslich ist. Mit den aus der erkalteten Lösung erhaltenen 
Krystallen wurde eine Verbrennung, Kalk- und Wasserbestimmung vorgenommen.

Das erbaltene Resultat führte zu der Formel:

$$
\mathrm{CaO}, \mathrm{C}_{20} \mathrm{H}_{14} \mathrm{O}_{14}+12 \mathrm{HO} \text {. }
$$

Die 12 Aeq. Wasser entweichen schon vollständig in Vacuum. Eine genauere Untersuchung wurde nicht vorgenommen, da sie uns zu weit von unserem Gegenstand entfernt haben würde.

Eigenschaften der Milchsäure.

Wir erbielten dic Milchsïure stets als einen elwas bräunlich gefärblen Syrup, welche lichtbraune Farbe durch die zur Reindarstellung nothwendige Aufmahme in Aether und nachheriges Abdestilliren desselben dunkler wurde, ohne dafs wir jedoch im Entferntesten eine sonslige Veränderung wahrgenommen hällen. Sie löst sich in jedem Verhailtnifs in Wasser, Alkohol und Aether, ertheilt diesen Flüssigkieiten einen rein sauren Geschmack und erhäll sich vollkommen unverändert in ihren Auflösungen. Wir komten sie durchaus nicht in fester Form erhalien, selbst bei einer Temperalur von -20 bis $24^{\circ}$ gelang uns diefs nicht.

\section{Milchsaure Salze.}

Allgeneine Eigenschaften. - Sie zeichnen sich alle durch ihre absolute Unlöslichlieit in Aether und die meisten durch ihre Schwerlöslichkeit in kallem Wasser und Alkohol aus. Auch von kochenden Alkohol werden nur wenige leich und in grofser Menge aufgelöst, aber das liochende Wasser besitzt diese Eigenschaft in hohem Grade.

Bei $100^{\circ}$ verlieren sie, mil Ausnahme des Nickelsalzes, welches sein drittes Aeq. Wasser erst bei $130^{\circ}$ abgiebt, ihr Krystallwasser und können die meisten eine Temperatur von $150-170^{\circ}$, ja rinige, wie das Zinksalz, eine von $210^{\circ}$, ohne zersetzt zu worden, ertragen. Wir fanden die Salze, welche 
wir krystallisirt erhalten konnten, sämmtlich duftbeständig, mehrere sogar, wie das Zink-, Eisen- und Kobaltsalz, bleiben selbst über Schwefelsäure constant, doch alle geben Krystallwasser im luftleeren Raum ab. Die Lösungen effloresciren sehr slark. Die Mlehızahl der Salze krystallisirt leicht, aber nur von wenigen, wie dem Kupfer - und Mangansalz, glückte es uns, wohlausgebildete, bestimmbare Krystalle zu erhalten; die aller übrigen sind unter die grofse Kategorie der Nadeln zu zählen.

Bei der Berechnung der Analysen wurden die Aequivalentgewichte $\mathrm{H}=1 ; \mathrm{C}=6$ und $\mathrm{O}=8$ zu Grunde gelegt.

Milchsaures Silberoxyd. - Dieses Salz wird gebildet, wenn man $\mathrm{AgO}, \mathrm{CO}_{2}$ mit Milchsäure kocht. Die Flüssignteil reagirt, wemn $\mathrm{AgO}, \mathrm{CO}_{2}$ im Ueberschurs angewendet wurde, vollkommen neultal und das Salz krystallisirt, hat man nicht sehr verdünnte Lösungen, in seidenglänzenden, gewölunlich warzenförmig gruppirter Nädclchen heraus, welche sich am Licht, namentlich bei erhöhter 'Temperatur, bald schwärzen. Es ist in warmem Alkohol leicht löslich, in kaltem beinahe ganz unlöslich und dic alkoholische Lösung erstarrt defshalb beim Erkalten zu einem krystallinischen Magma. Wird die alkoholische, sowie auch die wässerige Lösung längere Zeit gekocht, so nimmt sie eine blaue Farbe an, und es scheiden sich nach und nach braune Flocken aus. Auch wenn dic erkaltete alkoholische Lösung mil Aether verselzt wird, tritt diese Erscheinung, nur noch in ausgepräglerem Grade, ein und durch den Aether wird das Silbersalz vollkommen gefällt.

Das milchsaure Silberoxyd einer Temperalur von $80^{\circ}$ ausgeselzt, erleidet keine Zerselzung, auf $100^{\circ}$ erlitzt schmilzt es und die Zersetzung giebt sich durch Annahme einer scliwarzen Farbe und Gasentwickelung zu erkenuen. Das Salz, welches zor Analyse diente, wurde aus Wasser mohrmals umkrystallisirt, aus der wässerigen Lösung dorch Allohol präcipitirt und der 
Alkohol durch Aether, entfernt. Das so erhaltene Salz bei $80^{\circ}$ getrocknet lieferte folgende Resultate :

I. 0,8269 Grm. Substanz ergaben bei der Verbrennung mit Kupferoxyd 0,1887 $\mathrm{HO}$ und 0,548 $\mathrm{CO}_{2}$.

Bei einer Silberoxydbestimmung durch Glühen vorgenommen gaben 0,4805 Grm. Substanz 0,262 Ag $=0,2814 \mathrm{AgO}$.

II. Eine andere Portion bis das Gewicht constant blieb dem luftleeren Raum ausgesetzt, ebenfalls mit Kupferoxyd verbranut gab $0,6315 \mathrm{Grm}$. Substanz $0,1590 \mathrm{HO}$ und $0,4205 \mathrm{CO}_{2}$. $0,846 \mathrm{Grm}$. Substanz 0,4585 $\mathrm{Ag}=0,492 \mathrm{AgO}$.

In Procenten ausgedrückt :

I. II. berechnet nach

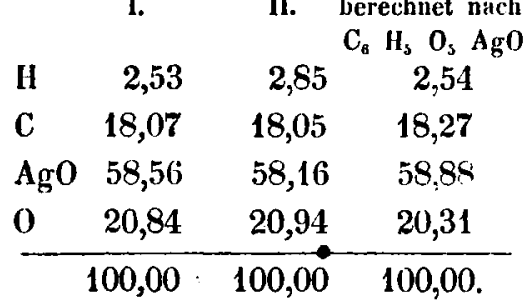

Man ersieht aus der Analyse II, dafs nicht alles Wasser im luftleeren Raum entfernt werden kann.

Wasserbestimmung.

I. Luftrockenes Salz bis $80^{\circ}$ erhitzt; es verloren $0,300 \mathrm{Gr}$. Substanz 0,0235 110.

II. $0,915 \mathrm{Grm}$. Substanz 0,081 HO.

Diels beträgt in 100 Theilen :

$$
\begin{array}{cc}
\text { I. } & \text { II. } \\
\mathbf{7 , 8 3} & \mathbf{8 , 8 5}
\end{array}
$$

gleich 2 Aequivalente, welche $8,37 \mathrm{Grm}$. verlangle. Zur Bestäligung des Wassergehaltes möge noch folgende Silberbestimmiung dienen :

0,4245 Grm. lufttrockener Substanz gaben beim Giühen $0,212 \mathrm{Ag}=0,2277 \mathrm{AgO}=53,64 \mathrm{pC}$.

Die Formel verlangt 53,99 . 
Das lufttrockene Salz hat demnach die Formel :

$$
\mathrm{AgO}, \mathrm{C}_{6} \mathrm{II}_{5} \mathrm{O}_{3}+2 \mathrm{HO} \text {. }
$$

Das bei $80^{\circ}$ und im luftleeren Raum behandelte :

$$
\mathrm{Ag} \mathbf{O}, \mathrm{C}_{6} \mathrm{H}_{5} \mathrm{O}_{5} \text {. }
$$

Milchsaures Kupferoxyd. - Nan kann es erhatten durch Behandeln des schwefelsauren Kupferoxydls nit nilchsaurem Baryt oder durch Kochen des kohlensauren Kupferoxyds mit Nilchsäure. Wählt man letzlere Methode und wendet kohlensaures Kupferoxd im Ueberschufs an, so bekomut man gewöhnlich neben dem neutralen, die weiter unten zu besprechenden basischen Salze, von welchen man es jedoch leicht durch Untlirystalliren oder Zusatz von elwas Mildusine tremen kann.

In beiden Fällen erlaalt man aber ans der wissmigen Lösung ein in grofsen, wollausgebildelen Krystallen anschicl'sendes Salz, welches jedoch alle Nüancen von blan und grün durchlaufen kann. Das grüne Salz kann durch Unkrystallisiren nicht in die blaue Modification übergeführt werden. Wir erhielten das mehr grüne Salz vorzugsweise nach der erstern Nethode. Der Güle des Hrn. Dr. Eltling haben wir eime Kirystallhestimmung dieses Salzes zu verdanken. Sie ist durch folgendes Schema ausgedrückt :

Das System ist zwei - und eingliedrigr.

$$
\begin{aligned}
& \text { perlmutterglänzend } \\
& (\infty \widetilde{\mathbf{P}} \infty) \quad=\infty \mathrm{a}: \mathrm{b}: \infty \quad \mathbf{c} 2 \text {. Seitenfläche } \\
& \text { glasglänzend } \\
& \infty \mathrm{P} \quad=\mathrm{a}: \mathrm{b}: \infty \mathrm{c} \text { verticales Prisma, }
\end{aligned}
$$

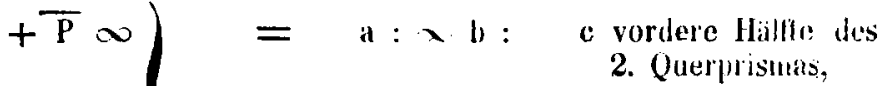

$$
\begin{aligned}
& \text { hintere lliallie des } \\
& \text { 2. Querprismas, }
\end{aligned}
$$

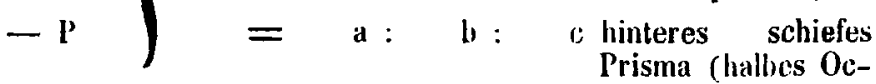

$$
\begin{aligned}
& (\infty \mathrm{P} \infty) \| \infty \mathrm{P}=121^{\circ} 19^{\circ} \\
& \text { taëder). } \\
& \infty \mathrm{P} . \quad=117^{\circ} 22^{\prime} \text {. }
\end{aligned}
$$


92 Engelhardt u. Maddrell, ïber die Milchsaure und

Der Habitus der Krystalle ist tafelförmig-prismatisch und sie zeigen viel Analogie mit denen des Gypses. Verselat man die wässerige Lösung mit nur wenig Alkohol, so bekommt man ein Salz, welches in dem Ansehen von dem aus Wasser krystallisirten so verschieden ist, dafs man ein anderes Salz vor sich zu haben glaubt, obgleich, wie die Analyse zeigen wird, in der Zusammenselzung nicht die mindeste Differenz obwaltet. Es zeigt nämlich unter andern stets eine viel liellere, beinahe himmelblaue Farbe und einen allasartigen Glanz. Das Kupfersalz löst sich in 6 Thl. kaltem und 2,2 Thl. kochendem Wasser, in 115 Thl. kallem und 26 Thl. kochendem Alkohol. Dic Lösung reagirt sehr stark sauer. Es kann bis $160^{\circ}$ erhitzt werden, ohne dafs eine Zerselzung vorgeht, sie beginnt erst bei 210", bei welcher 'Temperatur' es sich entzündet und verglimml.

I. 0,653 Grm. des bei $100^{\circ}$ getrockneten blauen Salzes lieferten $0,0266 \mathrm{HO}$ und $0,193 \mathrm{CO}_{2}$.

Kupferoxydbestimmung durch Glühen und Behandeln mit Salpetersäure angestellt. 0,5285 Grm. Substanz ergaben 0,1705 CuO.

II. $0,4842 \mathrm{Gr}$. grünes Salz gaben $0,183 \mathrm{HO}$ und $0,5275 \mathrm{CO}_{2}$. 0,666 Grm. Substanz gab $0,215 \mathrm{CuO}$.

In 100 Theilen sind enthallen :

I. II. berechnet nach

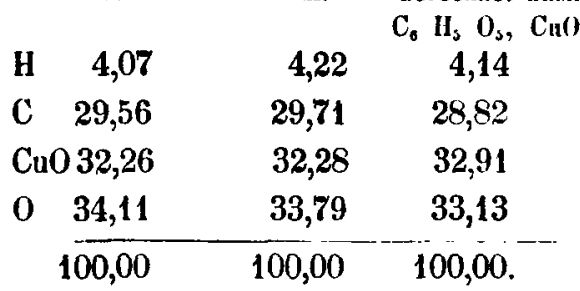

Wasserbestimmungen. - Schon über Schwefolsäure kann man das Kupfersalz sehr leicht von seinem ganzen Krystallwassergehall befreien, bei $100^{\circ}$ verliert es ihn aufserordenllich rasch. 
I. 1,879 Grm. Wlaues Salz his $100^{\circ}$ erhitzt gaben 0,244 Wasser ab.

II. 1,964 Grm. grünes Salz 0,2535.

Ill. 0,3965 aus einer wässerigen, mil wenig Alkohol vermischten Lösung krystallisirtes Salz 0,0535.

In Procenten ausgedrückt :

$$
\text { I2. } \quad \text { II. } \quad \text { III. }
$$

welcher Wassergchalt 2 Aequivalenten entspricht, welche beanspruchen : 12,98 .

Das lufttrockene Salz hat demnach die Formel :

$$
\mathrm{CuO}, \mathrm{C}_{6} \mathrm{H}_{5} \mathrm{O}_{3}+2 \mathrm{HO} \text {. }
$$

Basisches Kupferoxydsalz. - Es bildet sich, wie erwähnt, durch Kochen des kohlensauren Kupferoxyds mit Milchsäure und scheidet sich bald nach den Erkalten als hellblaues Salz ab. Es ist sowohl in kaltem, als kochendem Wasser äufserst schwer löslich und man kann es defshaib leicht von dem neutralen Salz befreien. Uebrigens hat uns die Analyse des zu verschiedenen Malen erhaltenen Salzes an die Hand gegeben, dafs wir verschiedene basische Salze voraus hatten und eine genauere Betrachtung zeigte auch, dafs die Masse nicht homogen sey, sondern dafs in dem hellen, breiigen Niederschlag dunklere, gröfsere und kleinere, compacte körnige Massen eines anderen Salzes zerstreut lagen. Durch Schlämmen wurden beide zu trennen versucht. Der specifisch schwerere körnige Theil ergab nachdem bei $100^{\circ}$ behandelt :

$0,3610 \mathrm{Grm}$. Substanz 0,0965 HO und 0,2965 $\mathrm{CO}_{2}$.

0,2175 Grm. Substanz 0,1085 CuO.

Entsprichi in Procenten :

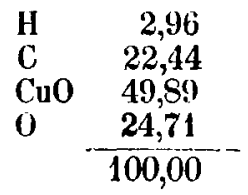

Die Formel $2 \mathrm{Cu}_{3} \mathrm{O}, \mathrm{C}_{8} \mathrm{HI}_{3} \mathrm{O}_{3}$ verlangt :

$$
\begin{array}{r}
3,12 \\
22,43 \\
49,52 \\
24,93 \\
100,00 .
\end{array}
$$


Man sicht also, dafs man dieses Salz von dem andern vollständig trennen kann, nicht aber auch umgekehrt, wie nachfolgende Analysen, die mil dem Product verschiedener Operationen vorgenommen wurden, zeigen werden.

Beide Salze verlieren schon über Schwefelsäure Wasser.

I. 0,2935 Grm. lufttrockne Substanz auf $100^{\circ}$ erhitzt ergab) einen Verlust von 0,041 .

$0,248 \mathrm{Grm}$. dieses bei $100^{\circ}$ getrockneten Salzes gaben $0,112 \mathrm{CuO}$.

II. 0,375 Grm. Substanz gaben 0,058 Wasser.

$0,315 \mathrm{Grm}$. lieferten 0,144 $\mathrm{CuO}$.

In Procenten :

$$
\begin{array}{lcr} 
& \text { I. } & \text { II. } \\
\text { HO } & 13,97 & 15,47 \\
\text { CuO } & 45,16 & 45,71 .
\end{array}
$$

Dals wir es also mil einem Gemenge zweier Salze zu thun hatten, beweist sowohl das verschiedene Resultal der beiden Analysen, als auch die $\mathbf{A b w e i c h u n g}$ von einfachen atomistischen Verhältnissen.

Milchsaures Cadmiumoxyd. - Kann sehr leicht erhalten werden, wenn man kohlensaures Cadmiumoxyd in Milchsäure auflöst. Es krystallisirt in kleinen, farblosen Nadeln und ist in 10 Theilen kalteın und 8 Theilen kochendem Wasser löslich, aber unlöslich in kaltem und kochendem Alkohol. Die Lösung reagirt vollkommen neutral.

Eine gesättigte Auflösung dieses Salzes in kochenden Wasser krystallisirt nicht beim Erkalten und um Krystalle zu erhalten Inul's man so weil abdampfen, bis sich eine Haut auf der Oberfläche bildet. Das so erhaltene Salz ist wasserfrei, denn ein luftrockener Zustand auf $100^{\circ}$ erhitzt verlor es nur $0,277 \mathrm{pC}$. Wasser, was wohl als hygroscopisches zu belrachten ist.

I. $0,644 \mathrm{Grm}$. bei $100^{\circ}$ getrockneten Salzes lieferte bei Verbrennung $0,2005 \mathrm{HO}$ und $0,5855 \mathrm{CO}_{2}$. 
Die Cadıniumbestimmung wurde mit kohlensaurem Kali anf nassem Wege vorgenommen.

$0,842 \mathrm{Grm}$. Substanz gaben 0,3695 Cadmiumoxyd.

II. 0,556 Grm. Substanz gaben $0,172 \mathrm{HO}$ und $0,502 \mathrm{CO}_{2}$.

In 100 Theilen wurde gefunden :

\begin{tabular}{|c|c|c|c|}
\hline & I. & II. & $\begin{array}{l}\text { berechnet nach } \\
\mathrm{C}_{6} \mathrm{H}_{5} \mathrm{O}_{3}, \mathrm{Cd} O\end{array}$ \\
\hline H & 3,45 & 3,42 & 3,45 \\
\hline $\mathrm{C}$ & 24,79 & 24,64 & 24,86 \\
\hline $\mathrm{CdO}$ & 43,88 & " & 44,07 \\
\hline 0 & 27,88 & $n$ & 27,62 \\
\hline & 100,00 & & 100,00 \\
\hline
\end{tabular}

Milchsaures Quec/ssilberoxydul. - Man erhält es mit Leichtigkeit beim Zusammenmischen einer warmen, höchst concentrirten Auflösung von milchsaurem Natron und einer gesättigten Lösung von salpetersaurenı Quecksilberoxydul. Wir haben das Verhältnifs von 2 Volumen Quecksilbersalz auf 1 Volum milchsaures Natron für das besle erkannt. Das Gemisch ist anfänglich farblos, wird aber bald darauf schön rosen - oder carminroth und setzt sich zu gleicher Zeit etwas metallisches Quecksilber ab. Man filtrirt. Nach 24 Siunden haben sich wundervolle, rosettenartig gebildete Gruppen von dem Salz abgeschieden, welche die Farbe der Lösung besitzen. Dieses Salz dürfte überhaupt wohl mit zu den schönsten gerechnet werden, welche die Chemie aufzuweisen hat. Ob die herrliche Farbe characteristisch für diese Verbindung, oder mehr zufällig ist, darüber haben wir keinen Aufschlufs. Die rothe Färbung stelit sich auch beim Vermischen der kalten Lösungen der beiden Salze, doch dann erst nach längerer Zeit, dar.

Es ist schwer löslich in kaltem und kochendem Wasser. Beim Kochen zersetzt es sich in metallisches Quecksilber und Oxydsalz. 
96 Engelhardt u. Maddrell, über die Milchsäure und

In kaltem Alkohol ist es un-, im kochendem schwerlöslich und wird durch letzleren unter Abscheidung eines weifsen scliweren Pulvers zersetzt. Die Lösungen reagiren stark sauer.

Analyse.

I. $0,485 \mathrm{Grm}$. Iufttrocknen Salzes lieferten $0,225 \mathrm{CO}_{2}$.

Eine Wasserbestimmung konnte nicht vorgenommen werden, da trolz aller Vorsichtsmafsregeln und Vorkehrungen immer Quecksilber in Chlorcalciumrohr vorhanden war.

Die Quecksilberoxydulbeslimmung wurde auf die bekanute Weise durch Glühen mit Natronkalk und unter genauer Beobachtung der in Fresenius analytischer Chemie angegebenen Specialitäten vorgenommen.

$0,8858 \mathrm{Grm}$. Substanz galen $0,5745 \mathrm{Hg}=0,5974 \mathrm{II}_{\mathbb{N}_{2}} \mathrm{O}$.

Wasserbestimmung : Bui $100^{\circ}$ wird das Salz dunkel gefärbt, doch nicht zersetzt, wie die aus der Verbrennung des luftrockenen Salzes erhallenen Resultate zeigen.

0,496 Grm. Substanz auf $100^{\circ}$ erhitzt erlitten einen Verlust von 0,028 Wasser.

II. $0,517 \mathrm{Grm}$. Substanz verbrannt lieferte $0,2335 \mathrm{CO}_{2}$.

100 Theile des luftrockenen Salzes enthalten demnach :

I. II. berechnet nach

$\begin{array}{lccc} & & & \mathrm{Hg}_{2} \mathrm{O}, \mathrm{C}_{6} \mathrm{H}_{5} \mathrm{O}_{3}+2 \mathrm{HO} \\ \mathrm{H} & \eta & \eta & 1,62 \\ \mathrm{C} & 12,65, & 12,321 & 11,72 \\ \mathrm{Hg}_{2} \mathrm{O} & 67,44 & \eta & 67,78 \\ 2 \mathrm{HO} & 5,64 & n & 5,86 .\end{array}$

Basisch milchsaures Quecksilberoxydsalz. - Wurde erhalten durch Kochen von $\mathrm{HgO}$ mit verdünnter Milchsäure bis die Auflösung gesättigt war. Um Kirystalle zu erhalten, wurde die Lösung bis zur Syrupconsistenz eingedampft. Es krystallisirten Salze heraus, wovon das cine gelb und im Wasser unlöslich, das 
andere farblos und leicht löslich war. Man behandelt die krystallisirte Masse mit kochendem Wasser, wo sich das farblose Salz leicht löst, das andere als ein hellgelbes Pulver zurückbleibt. Das letztere war jedoch nur in so geringer Menge vorhanden, dafs es keiner Untersuchung unterworfen werden konnte. Das andere Salz krystallisirt in stark glänzenden freien Prismen, die gewöhnlich concentrisch gruppirt sind und zeichnet sich vor allen übrigen durch seine grofse Neigung zu effloresciren aus. Es ist sehr leicht löslich in kaltem und kochendem Wasser, schwer löslich in kochendem und kaltem Weingeist und wird nicht beim Kochen zersetzt.

Die Lösungen reagiren stark sauer.

Analyse. Das Salz ist wasserfrei, denn bis $100^{\circ}$ erhitzt nahm es nicht um 1 Milligramm an Gewicht ab.

I. 1,315 Grm. des lufttrockenen Salzes gaben bei Verbrennung $0,5975 \mathrm{CO}_{2}$.

Die Quecksilberoxydbestimmung wurde auf die bei Oxydulsalz angegebene Weise vorgenommen und aus 1,2422 Grm. Substanz 0,84 Quecksilber $=0,9071$ Quecksilberoxyd erhalten.

II. 0,773 Grm. Substanz gaben $0,351 \quad \mathrm{CO}_{2}$.

Die gefundenen Verhältnisse führen zu der Formel :

$2 \mathrm{HgO}, \mathrm{C}_{6} \mathrm{H}_{5} \mathrm{O}_{5}$, welche in 100 Theilen verlangt :

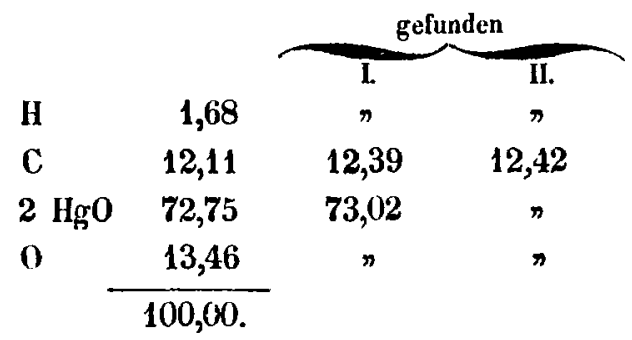

Basisch-milchsaures Zinnoxydul. - Kann erhalten werden, wenn man eine saure Auflösung von Zinnchlorür mit milchsaurem Natron mischt. Es setzt sich als ein weifses krystallinisches Pulver ab. Durch Auswaschen mit Wasser wird es 
vollkommen gereinigt. Behandelt man das Pulver mit kaltem Wasser, so löst sich keine Spur darin auf, mit kochendem Wasser zeigt die Flüssigkeit eine stark sauere Reaction und hat sich ein Minimum aufgelöst, so dafs Schwefelwasserstoff eine braune Färbung bewirkt. In kaltem und kochendem Alkohol ist das Salz absolut unlöslich.

Salzsäure löst es leicht aber Essigsäure erst nach längerem Kochen.

Es ist wasserfrei, denn im luftrockenen Zustand bis $100^{\circ}$ erhitzt erlitt es nur einen Verlust von $0,77 \mathrm{pC}$., was nicht 1 Aequivalent ausmacht.

I. Eine Verbrennung des bei $100^{\circ}$ behandelten Salzes lieferte von 0,8115 Grm. Substanz 0,143 Wasser und 0,5045 Kohlensäure.

Dic Zinnoxydulbestimmung wurde durch Verglimmen des Salzes und Behandeln mit Salpetersäure vorgenominen.

0,6205 Grm. Substanz gaben 0,44 Zinnoxyd $=0,393$ Zinnoxydul.

II. 0,868 Grm. Substanz gaben 0,549 Kohlensäure.

Die Resultate ergaben die Formel $(\mathrm{Sn}=58,93)$ :

$$
2 \mathrm{Sn} \mathrm{O}, \mathrm{C}_{0} \mathrm{H}_{5} \mathrm{O}_{5} \text {, }
$$

welehe in 100 Theilen verlangt :

\begin{tabular}{lrrc} 
& \multicolumn{2}{c}{ gefunden } \\
\cline { 2 - 3 } Kohlenstoff & 16,75 & 1. & If. \\
Wasserstoff & 2,33 & 1,96 & 17,17 \\
Zinnoxydul & 62,30 & 63,34 & $n$ \\
Sauerstoll & 18,62 & 17,75 & $n$ \\
\hline 100,00 & $100,00$.
\end{tabular}

Der Kohlenstoff und Zinnoxydulgehalt ist höchst wahrscheinlich wegen einer geringen Zersetzung des Salzes bei $100^{\circ}$, zu hoch ausgefallen. 
Milchsaures Zinnoxyd. - Versetzt man Zinnchlorid mit milchsaurem Natron, so erhält man weder einen Niederschlag, noch beim Abdampfen bis zur Syrupconsistenz Krystalle.

Milchsaures Bleioxyd. - Es gelang uns auf keine Weise, eine krystallisirte oder mit bestimmten Eigenschaften begabte Verbindung von Bleioxyd mit Milchsăure zu erhalten. Kocht man kohlensaures Bleioxyd mit Milchsäure, so bekommt man eine neutral reagirende Flüssigkeit, die an der Luft ein Häutchen, aus kohlensaurem Bleioxyd bestehend, absetzt und alsdann schwach sauer reagirt. Die Flüssigkeit trocknel über Schwefelsäure zu einer gummiartigen Masse ein, welche in gewöhnlichem, namentlich warmem Alkohol leicht löslich ist und sich durchaus nicht daraus krystallisirt erhalten läfst. Wendet man absoluten Alkohol an, so löst sich in der Kälte gar nichts, beim Kochen eine geringe Menge auf, die sich beim Erkalten vollständig als eine weifse, unkrystallinische, zähe, fadige, Eiweifsgerinsel sehr ähnlich sehende Masse ausscheidet. Aether löst von dem Syrup keine Spur auf. Wir versucliten eine basische Verbindung durch Behandeln des neutralen Bleisalzes mit basisch-essigsaurem Bleioxyd darzustellen, doch erhielten wir weder einen Niederschlag, noch Krystalle.

Milchsaures Uranoxyd. - Uranoxyd, erhalten durch Erhitzen von salpetersaurem Uranoxyd und Auslaugen mit kochendem Wasser, löste sich leicht in Milchsäure. Nachdem die Lösung bis zum Syrup eingedampft, so dafs sich Krystallinden auf den Wandungen des Gefäfses abzusetzen anfangen, scheidet sich beim Erkalten das Salz in hellgelben Krusten ab, welche sich in grofser Menge, in kaltem und kochendem Wasser lösen. Die Lösungen reagiren stark sauer und müssen, wie erwähnt, zur Syrupconsistenz gebracht werden, ehe das Salz sich in Krystallkrusten abscheidet. Die Auflösungen werden durch Sonnensirahlen zersetzt, die gelbe Farbe verwandelt sich zuerst in eine grüne und nachler schlägt sich ein 
braunes, keine Milchsäure enthaltendes Uranoxyd nieder. Von kaltem und kochendem Weingeist wird nur eine Spur des Salzes aufgenommen.

Analyse. Verbrennung. - Es wurde bei $100^{\circ}$ getronecktes Salz genommen. 0,8525 Grm. Substanz lieferten 0,1745 Wasser und 0,4965 Kohlensäure.

Zur Uranbestimmung liefsen wir das Salz verglimmen und reducirten das entstandene variabel zusammengeselzte Oxyd in Wasserstoffgas.

1,2215 Grm. Substanz gaben 0,7318 Uranoxydul $=0,7752$ Uranoxyd.

Es ergiebt sich aus den gefundenen Resultaten die Formel $\mathrm{U}=59,5$ :

$$
\mathrm{U}_{2} \mathrm{O}_{3}, \mathrm{C}_{6} \mathrm{H}_{3} \mathrm{O}_{5},
$$

welche in 100 'Theilen verlangt :

\begin{tabular}{lrr} 
Wasserstoff & 2,22 & gefunden \\
Kohlenstoff & 16,01 & 2,27 \\
Uranoxyd & 63,98 & 63,49 \\
Sauerstoff & 17,79 & 18,37 \\
\cline { 2 - 3 } & 100,00 & $100,00$.
\end{tabular}

Wasserbestimmung : Luftrocken bis auf $100^{\circ}$ erhitzt, verloren 1,239 Grm. Substanz 0,0175 Wassêr $=1,41$ pC., welche Menge keinem atomislischen Verhältnils entspricht und als mechanisch beigemengtes Wasser angesehen werden muls.

Milchsaures Antimonoxyd. - Antimonoxyd ist für sich liaum löslich in Milchsäure, aber wenn es mit saurem, milchsaurem Kali einige Zeit gekocht wird, so löst sich eine beträchtliche Quantität auf. Es liefsen sich jedoch keine Krystalle erhalten.

Milchsaures Eisenoxyd. - Ist nicht krystallisirbar. Die wässerige und alkoholische Lösung trocknen zu gelben amorphen Massen ein. 
Milchsaures Chromoxyd. - Chromoxydhydrat löst sich sehr leicht in Milchsäure, giet jedoch keine Krystalle, weder wenn die wässerige Lösung slark eingedampft wird, noch wenn man den so erhaltenen Syrup mit absolutem Alkohol und Aether behandelt.

Milchsaure Thonerde. - Das Thonerdehydrat ist fast unlöslich in Milchsäuro. Zerselzt man die schwefelsaure Thonerde durch milchsauren Baryt, so bekommt man zwar eine sehr viel Thonerde enthaltende Lösung, aus der sich aber auf keine Weise Krystalle erhalten lassen.

Milchsaures Eisenoxydul. - Man erhält es, wenn man nach Pagenstecher milchsaures Ammoniumoxyd mit Eisenchlorür vermischt und Weingeist zusetzt. Nach 24 Stunden hat sich das milchsaure Eisenoxydul krystallisirt ausgeschieden. Durch Abwaschen der Krystallmassen mit Weingeist und Umkrystallisiren und durch Kochen mit von Luft befreiten Wasser erhält man es absolut rein. Auch kann man es selir leicht durch Zersetzung des Eisenvitriols mittelst milchsauren Baryts erhalten. Da der schwefelsaure Baryt erst nachdem er sich abgesetzt hat, was einige Zeit dauert und auch nur bei Erwärmen der Flüssigkeit vollständig geschieht, abfiltrirt werden kann, so ist man genöthigt, um die Oxydation des Eisenoxyduls möglichsı zu vermeiden, die Zersetzung in einem Kolben und zwar kochend vorzunehmen. Zu dem Filtrat wird Weingeist geselzh, wo sich das Salz abscheidet und wenn man den in Weingeist so leicht löslichen milchsauren Baryl im Ueberschufs verwandte, durch blofses Abwaschen mit demselben rein erhalten werden kann. Diese Methode verdient wohl insofern einen Vorzug, da man ein bestimmtes Mafs in Händen hat, was bei der von Pagenstecher angegebenen nicht der Fall ist, da von den beiden Salzen, aus deren Umselzung es gebildet werden soll, das milchsaure Ammoniumoxyd sich nicht in fester Form erhalten, also auch keine entsprechende äquivalente Menge anwenden läfst. 
102 Engellardt u. Maddrell, über die Milchsäure und

Aus reinem Wasser krystallisirt das Salz in ziemlich grofsen, hellgelben Nadeln und aus mit Weingeist vermischtem setzt es sich in feinen, weifsen, nach dem Trocknen dicht verfilzten, seidenglänzenden Nädelchen ab. Es ist schwer löslich in kaltem, ziemlich löslich in kochendem Wasser und Alkohol. Die Lösungen reagiren stark sauer, färben sich an der Luft bald dunkelbraun, ohne jedoch ein basisches Eisenoxydsalz abzusetzen. Das trockene Salz ist vollkommen luftbeständig und das Gewicht bleibt auch über Schwefelsäure vollkommen constant. Bei einer Temperatur von $50-60^{\circ}$ fängt es an unter gleichzeitigem Verlust von Wasser braun gefärbt zu werden. Erhält man es bei dieser Temperatur längere Zeit, so wird es zuletzt beinahe schwarz, löst sich alsdann mit Leichtigkeit im Wasser und vermag nur noch wenig Silber aus dem salpetersauren Salz zu reduciren; alles Zeichen, dafs eine Oxydation Statt gefunden hat. Steigert man die Temperatur des längere Zeit bei $60^{\circ}$ behandelten, also beinahe ganz in milchsaures Eisenoxyd verwandelten Salzes, auf $120^{\circ}$, so giebt sich die Zersetzung der Milchsäure durch einen empyreumatischen Geruch zu erkennen. Im Vacuum giebt das milchsaure Eisenoxydul seinen ganzen Wassergehalt ab.

Analyse : $0,499 \mathrm{Grm}$. bei $100^{\circ}$ im Strom von Wasserstoffgas getrocknetes Salz gaben bei Verbrennung 0,1925 Wasser und 0,558 liohlensäure.

Eiscnoxydbestimmung : 0,483 Grm. lieferten nach dem Glühen und Behandeln mit Salpetersäure 0,1635 Eisenoxyd und 0,1471 Eisenoxydul.

Es ergiebt sich hieraus folgende Formel $(\mathrm{Fe}=28)$ :

$$
\mathrm{FeO}, \mathrm{C}_{6} \mathrm{H}_{5} \mathrm{O}_{5},
$$

welche in 100 'Theilen verlangt : 


\begin{tabular}{lrc} 
Wasserstoff & 4,27 & gefunden \\
Kohlenstoff & 30,77 & 30,46 \\
Eisenoxydul & 30,77 & 30,45 \\
Suuerstoff & 34,19 & 34,80 \\
\cline { 2 - 3 } & 100,00 & $100,00$.
\end{tabular}

Wasserbestimmung : 1,521 Grm. lufttrockene Substanz verloren im Strom von Wasserstoffgas auf $100^{\circ}$ erhitzt 0,290 Wasser $=19,13 \mathrm{pc}$., was 3 Aequivalenten entspricht, welche 18,75 pC. verlangen.

Das lufttrockene Salz hat also die Zusammensetzung :

$$
\mathrm{FeO}, \mathrm{C}_{6} \mathrm{H}_{5} \mathrm{O}_{5}+3 \mathrm{HO} \text {. }
$$

Milchsaures Zinkoxyd. Dargestellt durch Kochen des kohlensauren Zinkoxyds mit Milchsäure.-Beim Erkalten scheidet es sich, wenn die Lösung concentrirt in krystallinischen Krusten, wenn verdünnter, in feinen spiefsigen, doch slets eng zusaminenhängenden Krystallen ab. Es löst sich in 58 Theilen kaltem und 6 Theilen kochendem Wasser, ist beinahe unlöslich in kochendem und kaltem Alkohol und die Lösungen reagiren sauer. Es verliert über Schwefelsäure kein Wasser, kann aber im Vacuum ganz davon befreit werden.

Aalyse : Es wurde bei $100^{\circ}$ getrocknetes Salz angewendet.

I. 0,610 Grm. lieferten verbrannt 0,2255 Wasser und 0,6615 Kohlensäure.

II. 0,450 Grm. 0,1645 Wasser und 0,487 Kohlensäure.

Zinkoxydbestimmung vermittelst kohlensaurem Natron. 0,981 Grm. Substanz gaben 0,3285 Zinkoxyd.

Die Resultate ergeben die Formel $(\mathrm{Zn}=32,528)$ :

$$
\mathrm{Zn} \mathrm{O}_{2} \mathrm{C}_{6} \mathrm{H}_{5} \mathrm{O}_{5} \text {, }
$$

welche in 100 Theilen verlangt : 
104 Engelhardt u. Maddrell, über die Milchsăure und

\begin{tabular}{lrrr} 
& & \multicolumn{2}{c}{ gefunden } \\
\cline { 2 - 4 } Wasserstoff & 4,11 & 4,10 & \multicolumn{1}{c}{4,06} \\
Kohlenstoff & 29,62 & 29,57 & 29,52 \\
Zinkoxyd & 33,35 & 7 & 33,48 \\
Sauerstoff & 32,92 & 7 & 32,94 \\
\cline { 2 - 2 } & & & $\frac{100,00 .}{100,00}$
\end{tabular}

Wasserbestimmung.

I. 4,9685 Grm. luftrockenes Salz verloren bis $100^{\circ}$ erhitzt 0,904 Wasser.

Il. 3,589 Grm. 0,655 .

III. 1,924 Grm. vierzehn Tage im lufleeren Raume zeigten einen Verlust von $0,347=18,035 \mathrm{pC}$., bis $100^{\circ}$ erhitzt noch eine Abnahme von $0,0035=0,182 \mathrm{pC}$., in Summa $18,217 \mathrm{pC}$.

In 100 Theilen sind enthalten :

I. II. III.

$$
18,19 \quad 18,25 \quad 18,22,
$$

welcher Gehalt 3 Aecquivalenten gleichkommt, welche $18,18 \mathrm{pC}$. erfordern.

Die Zusammensetzung des luftrockenen Salzes ist demnach ausgedrückt durch die Formel :

$$
\mathrm{ZnO}, \mathrm{C}_{6} \mathrm{H}_{5} \mathrm{O}_{5}+3 \mathrm{HO} \text {. }
$$

- Das Zinksalz läfst sich bis auf $210^{\circ}$ erhitzen, wobei es nur eine höchst unbedeutende Zersetzung erleidet, wie folgende Angaben zeigen werden :

$4,0645 \mathrm{Grm}$. bei $100^{\circ}$ getrockneles, also wasserfreies Salz bis $120^{\circ}$ erhitzt verloren $0,0025=0,061 \mathrm{pC}$, von da bis $160^{\circ}$ noch $0,005=0,123 \mathrm{pC}$, bis $210^{\circ}$ constant, also in Summa 0,184 pC.

Milchsaures Nickeloxydul. - Kohlensaures Nickeloxydul mit Milchsäure gekocht, oder schwefelsaures Nickeloxydul durch milchsauren Baryt zersetzt, liefern apfelgrüne, waren die Lösungen 
verdünnt, zu büschelförmigen Gruppen vereinigte, vollkommen gleich zusammengesetzle Nädelchen; läfst man aus concentrirten Lösungen krystallisiren, so scheidet sich das Salz in krystallinischen Krusten ab. Es ist beinahe unlöslich in kaltem, oder ziemlich löslich in kochendem Wasser, unlöslich in kaltem und kochendem Alkohol und wird defslıalb aus der wässerigen Lösung das Salz in Gestalt eines Breies, der bald krystallinisch wird, durch Alkohol niedergeschlagen. Die Lösungen reagiren nur sehr schwach sauer.

Das Nickelsalz ist vollkommen Iuftbeständig, verliert aber schon über Schwefelsäure eine beträchlliche Quantität Wasser. Es enthält davon 3 Aequivalente, von welchen zwei bei $100^{\circ}$, das dritte erst bei $130^{\circ}$ entweicht.

Analyse : Zur Verbrennung wurden $0,520 \mathrm{Grm}$. bei $100^{\circ}$ getrockneter Substanz verwendet. Sie lieferten 0,224 Wasser und 0,5255 Kohlensäure.

Nickeloxydulbestimnung : $0,352 \mathrm{Grm}$. bei $134^{\circ}$ behandeltes, also wasserfreies, entsprechend $0,3787 \mathrm{Grm}$. bei $100^{\circ}$ getrocknetem Salz, ergaben nach dem Glühen und Oxydation mil Salpetersäure 0,1105 Nickeloxydul.

Die gefundenen Resultate erhalten mit Zugrundlegung von $\mathrm{Ni}=29,622$ durch die Formel :

$$
\mathrm{NiO}, \mathrm{C}_{6} \mathrm{H}_{3} \mathrm{O}_{5}+\mathrm{HO}
$$

einen Ausdruck. Sie verlangt :

\begin{tabular}{lrr} 
& & \multicolumn{1}{c}{ gefunden } \\
Wasserstoff & 4,70 & 4,79 \\
Kohlenstoff & 28,21 & 27,56 \\
Nickeloxydul & 29,48 & 29,18 \\
Sauerstoff & 37,61 & 38,47 \\
\cline { 2 - 3 } & 100,00 & 100,00
\end{tabular}

Der Kohlenstoffgehalt ist defshalb zu niedrig ausgefallen, weil, wie sich später bei der Wasserbestimmung ergeben wird, bei 
106 Engelhardt u. Maddrell, über die Milchsäure und

$100^{\circ}$ die 2 Aequivalente noch nicht ganz vollständig entwichen waren.

Wasserbestimmung.

I. 1,395 Grm. lufttrockener Substanz verloren bis $100^{\circ}$ erhilzt 0,1555 Wasser, 0,706 Grm. weiter auf $130^{\circ}$, abermals 0,0565 Wasser.

II. $0,655 \mathrm{Grm}$. bis $100^{\circ}, 0,073$ auf $130^{\circ}$ noch 0,0485 Wasser.

Diefs entspricht in 100 Theilen für das bis $100^{\circ}$ erhitzte Salz :

$\begin{array}{cc}\text { I. } & \text { II. } \\ 11,15 & 11,15 \text {, }\end{array}$

welcher Gehalt 2 Aequivalente beträgt, welche verlangen :

$$
12,36 \text {. }
$$

Für das bis $130^{\circ}$ erhitzte Salz :

$$
\begin{array}{cc}
\text { I. } & \text { II. } \\
18,24 & 18,55,
\end{array}
$$

was 3 Aequivalente ausmacht, welche erfordern 18,54.

Das einer Temperatur von $130^{\circ}$ ausgesetzt gewesene Salz hat demnach die Formel :

$$
\mathrm{NiO}, \mathrm{C}_{6} \mathrm{H}_{5} \mathrm{O}_{5} \text {; }
$$

das einer Temperatur von $100^{\circ}$ ausgesetzt gewesene

$$
\mathrm{NiO}, \mathrm{C}_{6} \mathrm{H}_{5} \mathrm{O}_{5}+\mathrm{HO} \text {; }
$$

das lufttrockene Salz

$$
\mathrm{NiO}, \mathrm{C}_{6} \mathrm{H}_{5} \mathrm{O}_{5}+3 \mathrm{HO} \text {. }
$$

Milchsaures Kobaltoxydul. - Wird erhalten durch Kochen des Kobaltoxydhydrats mit Milchsäure. Es stellt ein pfirsichblüthrothes, ganz den Typus des Nickelsalzes besitzendes Salz dar. In den Löslichkeitsverhältnissen und dem Verhalten der wässerigen Lösung zu Weingeist copirt es ebenfalls vollkommen das milchsaure Nickeloxydul, auch reagirt es wie dieses nur sehr schwach sauer. Es ist luftbeständig und verliert über Schwefelsäure kein Wasser, wohl aber im Vacuum.

Analyse : Es wurde bei $100^{\circ}$ getrocknetes Salz angewendet. 
I. Verbrennung : $0,4480 \mathrm{Grm}$. Substanz bildeten 0,1730 Wasser und 0,4975 Kohlensäure.

Kobaltoxydulbestimmung : Durch gelindes Glühen des Salzes wurde die Verbindung $\mathrm{Co}_{3} \mathrm{O}_{4}$ dargestellt und hieraus das Oxydul berechnet.

0,778 Grm. Substanz ergaben $0,2625 \mathrm{Co}_{3} \mathrm{O}_{4}$.

Il. 0,438 Grm. Substanz ergaben 0,1535 Wasser und 0,486 Kohlensäure.

Aus dem erhaltenen Resultat geht die Formel hervor :

$$
\mathrm{CoO}, \mathrm{C}_{6} \quad \mathrm{H}_{5} \mathrm{O}_{5} \text {, }
$$

welche verlangt $\left(\mathrm{Co}_{0}=29,568\right)$.

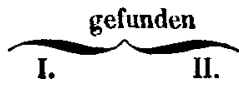

\begin{tabular}{lrrr} 
Wasserstoff & 4,22 & 4,46 & 3,89 \\
Kohlenstoff & 30,36 & 30,36 & 30,26 \\
Kobaltoxydul & 31,63 & 31,49 & " \\
Sauerstoff & 33,74 & 33,69 & " \\
\cline { 2 - 3 } & 100,00 & $100,00$. &
\end{tabular}

Wasserbestimmung.

I. 1,4185 Grm. lufttrocknes Salz bis auf $100^{\circ}$ erhitzt verloren $0,264 \mathrm{Grm}$. Wasser.

II. 0,3965 Grm. 0,072 .

III. 0,9655 Grm. 0,1835 .

In 100 Theilen sind demnach enthalten :

$\begin{array}{ccc}\text { I. } & \text { II. } & \text { III. } \\ 18,61 & 18,16 & 19,00\end{array}$

gleich 3 Aequivalenten, welche erfordern 18,55.

Das lufttrockene Salz hat folglich die Zusammensetzung :

$$
\mathrm{CoO}, \mathrm{C}_{6} \mathrm{H}_{5} \mathrm{O}_{5}+3 \mathrm{HO} \text {. }
$$

Milchsaures Manganoxydul. - Wir erhielten es theils in farblosen, theils in schwach amelhystfarbigen, stark glänzenden Krystallkrusten, durch Kochen des kohlensauren Manganoxyduls mit Milchsäure. Es ist ziemlich löslich in kaltem, leicht in ko- 
chendem Wasser, unlöslich in kaltem, leichter in kochendem Alkohol. Wird die wässerige Lösung mit Weingeist versetzt, so scheidet sich ein in den physikalischen Eigenschaften von dem reinen Wasser krystallisirten sehr abweichendes Salz ab, was jedoch, wie die Analyse zeigen wird, in der Zusammensetzung mit diesem vollkommen identisch ist. Die Lösungen reagiren ganz neutral und man kann aus der wässerigen dureh freiwilliges Verdunsten grofse, schöne, wohlausgebildete Krystalle erhallen. Herr Dr. Ettling hatte die Güte, eine krystallographische Bestimmung derselben vorzunehmen und er fand sie dem zwei - und eingliedrigen System angehörig. Wie beim Kupfersalz, so zeigen auch hier die verschiedenen Flächen verschiedene Arten des Glanzes.

$$
\begin{aligned}
& \text { So ist }(\infty \breve{\mathrm{P}} \infty) \text { perlmutterglänzend } \\
& \infty \overline{\mathrm{P}} \infty \text { glasglänzend und } \\
& \begin{array}{l}
+\overline{\mathrm{P}} \infty \\
-\overline{\mathrm{P}} \infty
\end{array} \mid \text { sind drusig. }
\end{aligned}
$$

Die Krystalle besitzen einen dicken Habitus in der Richtung von $\infty \breve{\mathbf{P}} \infty$ und zeigen überhaupt eine grofse Aelnnlichkeit mit denen des Zuckers. .

Das Saiz ist vollkommen luftbeständig, verliert aber über Schwefelsäure eine beträchtliche Menge Wasser, nämlich an 9 pC. Es fiel uns auf, dafs zwei verschiedene Porlionen, die über Schwefelsäure, bis sie constant waren, gestanden, beinahe gleich viel an Gewicht verloren hatten, nämlich die eine 9,67 , die andere $9,65 \mathrm{pC}$., obgleich dieser Verlust keinem Atomverhältnifs entspricht. Im luftleeren Raum scheinen vom Salz zwei Aequivalente $\mathrm{zu}$ entweichen.

Analyse : Es diente zu derselben, das aus der mit Weingeist verselzten wässerigen Lösung krystallisirte Salz.

$0,4965 \mathrm{Grm}$. bei $100^{\circ}$ getrocknetes Salz lieferten bei der Verbrennung 0,193 Wasser und 0,557 Kohlensäure. 
Manganoxydulbestimmung : Sie wurde mit dem durch starkes Glühen des Salzes erhaltenen Manganoxydoxydul vorgenommen.

$0,720 \mathrm{Grm}$. bei $100^{\circ}$ behandeltes Salz ergaben $0,237 \mathrm{Grm}$. Manganoxydoxydul, entsprechend 0,220 Manganoxydul.

Hieraus läfst sich die Formel entwickeln :

$$
\mathrm{MnO}, \mathrm{C}_{6} \mathrm{H}_{5} \mathrm{O}_{3} \text {, }
$$

welche beansprucht : $\mathrm{Mn}=27,716$.

\begin{tabular}{lrr} 
Wasserstoff & 4,28 & \multicolumn{1}{c}{ gefunden } \\
Kohlenstoff & 30,84 & 30,61 \\
Manganoxydul & 30,60 & 30,56 \\
Sauerstoff & 34,28 & 34,52 \\
\cline { 2 - 3 } & 100,00 & $100,00$.
\end{tabular}

\section{Wasserbestimmung :}

I. Aus Wasser krystallisirtes Salz. 2,001 Grm. vom lufttrockenen Zustand auf $100^{\circ}$ erhitzt, gaben 0,374 Gru. Wassor ab.

II. Aus weingeisthaltigem Wasser angeschossenes milchsaures Manganoxydul. 1,5565 Grm. 0,3075 Grm. W'asser.

In Procenten ausgedrückt :

I.

18,69
II.

19,77 ,

oder 3 Aequivalente, und es würde demnach dem luftrockenen Salz die Formel :

$$
\mathrm{MnO}, \mathrm{C}_{6} \mathrm{H}_{5} \mathrm{O}_{s}+3 \mathrm{HO}
$$

angehören.

Milchsaure Bittererde. - Die hio und da mit kleinen, stark glänzenden, nicht näher zu bestimmenden Prismen versehenen Krystallkiusten, welche man erhült, wenn man schwefelsaure Bittererde mit milchsaurem Baryt zerselzt, oder kohlensaure Billererde mit Milchsäure kocht, zeigen sich vollkonmen identisch. Das Salz ist in gewölnnlichem und absolutem Alkohol, sowohl kaltem als warmem, als unlöslich $\mathrm{zu}$ betrachten. Sechs 
Theile kochendes und 28 Theile kaltes Wasser, sind zu seiner Lösung erforderlich. Das Salz reagirt vollkommen neutral, und dampft man die Lösungen im Wasserbade zur Trockene, so bekommt man ein herrlich atlasglänzendes, silberweilses, wasserfreies Product, welches namentlich in Sonnenlicht eine prachtvolle Erscheinung darbietet. Die Angabe, dafs die milchsaure Bittererde verwittere, können wir durchaus nicht bestätigen, denn das Salz drei Wochen lang der Luft exponirt, hatte nicht den geringsten Gewichtsverlust erlitten. Selbst über Schwefelsäure hatte es erst nach langer Zeit eine geringe Portion Wasser abgegeben; im Vacuum entweichen jedoch bald bedeutende Quantitäten.

\section{Analyse :}

I. $0,4845 \mathrm{Grm}$. bei $100^{\circ}$ getrockneter Substanz lieferten, mit Kupferoxyd verbrannt, 0,217 Grm. Wasser und 0,6295 Grm. Kohlensäure.

Bittererdebestimmung : 0,6455 Grm. Substanz gaben 0,3525 Grm. pyrophosphorsaure Bittererde $(P=31,436)$, welche 0,1291 Grm. Bittererde enthalten.

II. 0,4207 Grm. Substanz, ebenfalls mit Kupferoxyd verbrannt, gaben 0,1885 Grm. Wasser und 0,547 Grm. Kohlensäure.

Diesen Resultaten entspricht die Formel : $\mathrm{MgO}, \mathrm{C}_{16} \mathrm{H}_{5} \mathrm{O}_{3}$, welche verlangt :

\begin{tabular}{lrrr} 
& & \multicolumn{2}{c}{ gefunden } \\
Wasserstoff & 4,92 & 4,97 & \multicolumn{1}{c}{ II. } \\
Kohlenstoff & 35,41 & 35,44 & 35,46 \\
Bittererde & 20,32 & 20,00 & " \\
Saucrstoff & 39,35 & 39,59 & n
\end{tabular}

Wasserbestimmung : 1,977 Grm. luftrockene Substanz verloren bis $100^{\circ}$ erhitzt $0,4175=21,12 \mathrm{pC}$. oder 3 Aequivalente, welche erheischen : $21,017 \mathrm{pC}$. 
Das luftrockene Salz hat folglich die Zusammenselzung :

$$
\mathrm{MgO}, \mathrm{C}_{6} \mathrm{H}_{5} \mathrm{O}_{5}+3 \mathrm{HO} \text {. }
$$

Milchsaure Kalkerde. - Man stellt sie durch Kochen des kohlensauren Kalks mit Milchsäure dar. Sie schiefst aus der wässerigen concentrirten Lösung in Gestalt von harten Körnern, welche aus concentrisch strahlig gruppirten Krystallen bestehen und viel Aehnlichkeit mit Sago zeigen, an. Ueberläfst man die Lösungen der freiwilligen Verdunstung, um deutlichere Krystalle zu erhalten, so efflorescirt das Salz aufserordentlich stark und die Wandungen des Gefäfses bedecken sich mit blumenkohlartigen, dendritischen Massen, ohne dafs man seinen Zweck erreicht. Das Salz löst sich in jedem Verhältnifs in kochendem Wasser und gewöhnlichem Alkohol, da es bei diesen Temperaturen in seinem Krystallwasser schmilzt, bedart aber 9,5 Theile kaltes Wasser zu seiner Lösung. In kaltem Weingeist ist der milchsaure Kalk vollkommen unlöslich, und es scheint, als wenn auch bei Temperaluren, die den Koclppunkt des Weingeists nicht erreichen, diefs der Fall sey, wenigstens fanden wir nur Spuren desselben bei $50^{\circ}$ in Weingeist gelöst, so dafs ihm überhaupt das Vermoggen, von Weingeist aufgenommen $\mathrm{zu}$ werden, abginge. Die Unlöslichkeit des milchsauren Kalks in absolutem Alkohol, dessen Siedepunkt tiefer liegt als der des gewöhnlichen, spricht ebenfalls für diese Annahme.

Aus der alkoholischen Auflösung setzt sich der milchsaure Kalk als ein Krystallbrei $a b$, der merkwürdiger Weise denselben Krystallwassergehalt zeigt, als das aus Wasser erhaltene Salz. Der milchsaure Kalk reagirt vollkommen neutral und ist durchaus luftbeständig. Er giebt sowohl über Sshwefelsäure, als auch im luftleeren Raum sein Krystallwasser leicht ab und man kann ihn durch längeres Behandeln in letzterem hiervon gänzlich befreien.

Analyse :

I. $0,642 \mathrm{Grm}$. bei $100^{\circ}$ getrockneter Substanz lieferten, beim 
Verbrennen mit chromsaurem Bleioxyd, 0,2745 Grm. Wasser und 0,766 Grm. Kohlensäure.

Kalkbestimmung : Sie wurde als schwefelsaurer Kalk auf nassem Wege bewerkstelligt : 0,9405 Grm. Substanz gaben 0,584 Grm. schwefelsauren Kalk.

II. 0,4497 Grm. Substanz, ebenfalls mit chromsaurem Bleioxyd verbrannt, ergaben $0,191 \mathrm{Grm}$. Wasser und 0,5405 Grm. Kohlensäure.

Die gefundenen Verhältnisse entsprechen der Formel :

$$
\mathrm{Ca}=20,0, \mathrm{CaO}, \mathrm{C}_{6} \mathrm{H}_{3} \mathrm{O}_{3} \text {, }
$$

welche verlangt :

\begin{tabular}{|c|c|c|c|}
\hline & & \multicolumn{2}{|c|}{ gefunden } \\
\hline & & I. & II. \\
\hline Wasserstoff & 4,59 & 4,75 & 4,72 \\
\hline Kohlenstoff & 33,03 & 32,55 & 32,78 \\
\hline Kalkerde & 25,69 & 25,56 & $n$ \\
\hline Sauerstoff & 36,69 & 37,14 & $n$ \\
\hline & 100,00 & 100,00 . & \\
\hline
\end{tabular}

Wasserbestimmung : Sämmtliches Krystallwasser geht bei $100^{\circ}$ fort, wie man aus der Bestimmung ersehen wird, und müssen wohl die neuesten Angaben $W$ ackenroder's ${ }^{*}$ ), nach welchem das fünfte Aequivalent erst bei $130^{\circ}$ und darüber unter geringer Zersetzung des Kalksalzes entweichen soll, auf einem Beobachtungsfehler beruhen, und folglich die aus diesem Verhalten geschöpften Consequenzen unrichtig seyn.

I. 4,4295 Grm. Substanz verloren, bei $100^{\circ}$ erbitzl, 1,294 Grm. Wasser.

Il. 0,\$94 Grm. Substanz 0,2585 Grm. Wasser.

III. 1,068 Grm. aus I'eingeist krystallisirte Substanz 0,313 Grm. Wasser.

*) Arch, d. Pharm, Bd. XI.VII 2. R. S. 2 fil. 
II Procenten ausgedrück! :

$\begin{array}{ccc}\text { I. } & \text { II. } & \text { II. } \\ 29,23 & 28,91 & 29,30\end{array}$

gleich 5 Aequivalenten, welche erheischen : $29,22 \mathrm{pC}$.

II. Der Versuch gab defshalb weniger, obgleich viele Stunden im Luflbad, weil das Kalksalz durch zu schnelles Erhitzen geschmolzen und so das Entweichen des Wassers erschwert war. Man kann diesen Uebelstand umgehen, wenn man das Salz zuerst einer Temperatur von $70-80^{\circ}$ ausgeselzl, wo dann ein grofser Theil des Krystallwassers forlgebt. Der milchsaure Kalk kann bis $180^{\circ}$ ohne Zersetzung erhitzt werden, bei $220^{\circ}$ war er geschmolzen und halle $1,17 \mathrm{pC}$. an Gewicht verloren, auch hatle das Luftbad einen empyreumalischen Geruch angenommen.

Milchsaure Kalkerde mit Chlorcalcium. - Dieses Salz entsteht, wenn man die wässerige Lösung des milchsauren Kalks mit einem Ueberschufs von Clilorcalcium versetzt und stark eindampft. Es krystallisirt in wohl characlerisirten, prisnalischen, dern Kalksalz nicht entfernt ähnlich sehenden luftbeständigen Irrystallen heraus. Un sie von dem üherschüssigen Chlorcalcium zu befreien, läfst man sie auf Fliefspapier abtrocknen und wascht sie mit gewöhnlichem lialten Alkohol, in welchem sie ziemlich schwer löslich sind, ab. Es ist aus dem Grunde nöthig, Chlorcalcium im Ueberschufs anzuwenden, weil einerseits eine Verunreinigung durch milchsauren Kalk vermieden wird, und dann, weil wir gefunden, dafs wenn man durch Umkrystallisiren aus Wasser das Salz von Chlorcalcium zu befreien sucht, man einen Körper, welcher iı seinen physikalischen Eigenschaften dem reinen Kalksalz mehr ähnelt und auch nach oberflächlichen Versuchen weniger Chlor zu entlalten schicn, bekommt, also wohl ein milchsaurer lialk mit venigem Clilorcalcium seyn mag. Es ist gar nicht mowahrscheinlich, dafs durch wiederholtes Uinkrystallisiren der milchsaure Kalk wieder vollkommen rein erhallen Annal. A. Chenice u. Phatm. LXIII. Bd. I Heft. 
werden kann; jedoch können die unlen anzuführenden Resultale der Analyse, welche mit ganz verschiedenen Portionen angestellt wurden, die distincten Eigenschaften dieses Körpers und der Umstand, dafs man ihn auf die angegubene Methode unfehlbar erhält, über die Existenz eines Doppelsalzes keinen Zweifel lassem. Es ist in Wasser und kochendem gewöhnlichem Weingeist sehr leicht löslich, von kaltem absolutem Alkohol wird nur wenig aufgenommen, von kochendem ziemlich viel.

Zur Analyse wurde das mit Alkohol abgewaschene lufttrockene, und hierauf bis $110^{\circ}$ erhitzte Salz verwendet.

Verbrennung : 0,5015 Grm. Substanz mil chromsaurem Bleioxyd verbrannt, lieferten 0,1555 Grm. Wasser und 0,387 Grm. Kohlensäure.

Chlorbestimmung : 0,385 Grm. Substanz gaben 0,3232 Grm. Chlorsilber $=0,0799$ Chlor.

Kalkbestimmung : 0,545 Grm. Substanz gaben durch kleesaures Ammoniak bestimmt, 0,3168 Grm. kohlensauren Kalk = 0,1774 Kalkerde $=32,550 \mathrm{pC}$.

Die Zusammenstellung der Resultate ergiebt die Formel :

$$
\left(\mathrm{Ca} \mathrm{Cl}+\mathrm{CaO}, \mathrm{C}_{6} \mathrm{H}_{5} \mathrm{O}_{5}\right)+\mathrm{HO} \text {, }
$$

also Chlorcalcium, in welchem das zweite Aequivalent Wasser durch milchsauren Kalk substituirt ist.

Sie verlangt :

\begin{tabular}{lrc}
\multicolumn{3}{c}{$\mathrm{Cl}=35,463$ und $\mathrm{Ca}=20}$. \\
Wasserstoff & 3,46 & $\begin{array}{c}\text { gefunden } \\
3,45\end{array}$ \\
Kohlenstoff & 20,75 & 21,14 \\
Kalkerde & 16,14 & 16,16 \\
Chlor & 20,44 & 20,75 \\
Calcium & 11,53 & 11,71 \\
Sauerstoff & 27,68 & 26,79 \\
\cline { 2 - 3 } & 100,00 & $100,00$.
\end{tabular}


Wasserbestimmung :

I. Das lufttrockene Salz auf $110^{\circ}$ erhitzt, ergaben 1,191 Grin. Substanz 0,2555 Grm. Wasser.

II. 0,806 Grm. 0,184 Grm. Wasser.

In 100 Theilen ausgedrückt :

$$
\begin{array}{cc}
\text { I. } & \text { II. } \\
21,453 & 22,82
\end{array}
$$

gleich 5 Aequivalenten, welche 20,60 pC. beanspruchen.

Die Zusammensetzung des Iufttrockenen Salzes würde hiernach durch die Formel :

$$
\left(\mathrm{Ca} \mathrm{Cl}+\mathrm{CaO}, \mathrm{C}_{6} \mathrm{H}_{5} \mathrm{O}_{5}\right)+6 \mathrm{HO}
$$

ausgedrücht seyn. Das bei $110^{\circ}$ behandelte Salz ist nicht zerfliefslich.

Milchsaure Slrontianerde. - Kohlensaure Strontianerde mit Milchsäure gekocht, bildet ein neutral reagirendes, dem Kalksalz in den physikalischen Eigenschaften sehr analoges Silz.

Die Constitution des Salzes wurde aus eincr Stronlianbestimmung abgeleitet; sie ist in lufttrocknen Zustand $\mathrm{Sr}=43,730$ $\mathrm{Sr} \mathrm{O}, \mathrm{C}_{6} \mathrm{H}_{5} \mathrm{O}_{5}+3 \mathrm{HO}$,

im bei $100^{\circ}$ behandelten : $\mathrm{Sr} \mathrm{O}, \mathrm{C}_{6} \mathrm{H}_{5} \mathrm{O}_{5}$, wic folgende Daten zeigen werden.

Strontianbestimmung : Sie wurde auf nasse!n Wege mit Schwefelsäure und Weingeist vorgenommen und dazu bei $100^{\circ}$ behandeltes Salz angewandt.

0,6455 Grm. Substanz gaben 0,447 Grm. schwefelsauren Strontian $=0,2519$ Strontianerde $=39,02 \mathrm{pC}$.

Das wasserfreie Salz verlangt $38,97 \mathrm{pC}$.

Wasserbestimmung bei $100^{\circ}: 1,4375$ Grm. Substanz gaben 0,2545 Grm. Wasser $=17,70$ pC. 3 Aequivalent $=16,90 \mathrm{pC}$. 
Neutrale milchsaure Baryterde. - Kocht man kohlensaure Baryterde mit Milchsäure, so löst sie sich leicht auf und man erhält cine neutral reagirende Flüssigkeit, aus der jedoch keime Krystalle zu belominen sind. Ueber ihr Verhalten zu Weingeist und Aether kann das beim Bleisaly angeführle gelten. Es gelang uns, ein saures Salz darzustellen, von welchem weiler unten die Rede seyn soll.

Milchstares Kali. - Wird kohlensaures Kali mit Milchsäure gesältigt und lelzlere in geringem Ueberschufs zugeselzl, so bekommt man beim Eindampfen einen Syrup, aus dem keine Krystalle gewonnen werden können. Auch heim langsamen Verdunsten der Flüssigkicit über Schwefelsäure und in luftleeren Raum, sowie durch Behandeln des erhalienen Syrups mil Alkohol, Aether etc., bekamen wir stets nur eine_anurphe Masse zu Gesicht. Wird die weingeislige Lösung mit wenig Aether versetzl, so scheidet sich zwar anfänglich ein fester, aber unkrystallinischer Körper aus, der auch bald wieder zu einem Syrup zusammenfliefst und eine von Aether scharf getrennte Schicht bildet.

Milchsaures Natron. - Es gilt dasselbe wie bein Kalisalz.

Milchsaures Ammoniumoxyd. - Auch bei diesem Körper, den einige Chemiker krystallisirt crhalten haben wollen, können wir mit Bestimmiheit auf das Verhalten der Lösungen des Kalisalzes verweisen. Einen Versuch, der uns sicher das Erhalten von Krystallen hoffen liefs, könuen wir doch nicht unerwähnt lassen.

Wir lösten nämlich die Milchsäure in Aether und leiteten trockenes Ammoniakgas hindurch. Bei der erslen Einwirkung zeigten sich auch Spuren einer krystallinischen Verbindung, aber dic Operation weiter fortgesetzt, löste sich Alles wieder in einen Syrup auf, über welchem sich der Aether vollkommen rein abgeschieden halte. Werden die Lïsungen des Ammoniaksalzes 
erwärmt, so geht Aınmoniak weg und sie zeigen eine saure Reaction.

\section{Saure Salze der Milchsäure.}

Saurer milchsaurer Baryt. - Versetzt man den neutralen milchsauren Baryt mit gerade so viel Milchsäure, als schon darin vorhanden, so bekommt man ein deutlich lirystallisirtes, äufserst festes, stark sauer reagirendes Salz. Um es von dem möglicherweise vorhandenen neutralen Barytsalz, oder der überschïssigen Milchsäure zu befreien, wàscht man es mit gewöhnlichem Alkohol, in dem es nicht sehr löslich ist, ab. Die Krystalle sind vollkommen luftbeständig, bleiben auch über Schwefelsäure und im Vacuum vollkommen constant und lösen sich ziemlich leicht in Wasser.

Die Analyse wurde mit luftrockenem Salz angestellt.

I. Verbrennung : Sie wurde mit chromsaurem Bleioxyd vorgenommen und am Ende eine sehr starke Hitze gegeben. 0,4985 Grm. Substanz lieferten 0,199 Grm. Wasser und $0,5285 \mathrm{Grm}$. Kohlensäure.

Barytbestimmung : Auf nassem Wege vermillelst Schwefelsäure. 0,6035 Grm. Substanz galıen 0,2838 Grm. schwefelsauren Baryt $=0,187$ Baryterde.

II. Verbrennung : Ebenfalls mit chromsaurem Bleioxyd angestellt. 0,4965 Grm. Substanz lieferten 0,2015 Grm. Wasser und 0,5255 Grm. Kohlensüure.

Barytbestimmung : Das Salz wurde stark gegliiht, mit Schwefelsäure behandelt und abermals eine starke Hitze gegeben. 0,659 Grm. gaben 0,3055 Grm. schwefelsauren Baryt $=0,2008$ Grm. Baryterde.

III. Barytsalz : Wie bei II. verfahren. 0,632 Grm. lieferten 0,295 Grm. schwefelsauren Baryt $=0,194$ Baryterde.

Die gefundenen Verhälnisse entsprechen der Formel : Ba $=68,663$, 


$$
\mathrm{BaO}, \mathrm{C}_{6} \mathrm{H}_{5} \mathrm{O}_{5}+\mathrm{HO}, \mathrm{C}_{6} \mathrm{H}_{5} \mathrm{O}_{3} \text {, }
$$

welche verlangt :

\begin{tabular}{lrrrc} 
& & \multicolumn{3}{c}{ gefunden } \\
\cline { 3 - 5 } Wasserstoff & 4,44 & 4,41 & 4,51 & II. \\
Kohlenstoff & 29,07 & 28,28 & 28,86 & " \\
Baryterde & 30,96 & 30,99 & 30,47 & 30,70 \\
Sauerstoff & 35,53 & 36,32 & 36,16 & " \\
\cline { 2 - 5 } & 100,00 & 100,00 & $100,00$.
\end{tabular}

Wird das luftrockene Salz bis auf $100^{\circ}$ erhitzt, so sinkt es etwas zusammen, das Luftbad nimmt empyreumalischen Geruch an, und in einem Fall ergab sich ein Verlust von $2,99 \mathrm{pC}$., in eincm anderen von $3,98 \mathrm{pC}$.

Saure milchsaure Kalkerde. - Verfährt man bei der Darslellung auf analoge Weise wie beim Barytsalz, so bestehen die ersten Irystallisationen aus neutralem milchsaurem Kalk. Dampft man zur vollständigen Abscheidung desselben, welche, da die Löslichkeitsverhältnisse so sehr verschieden sind, leicht bewerkstelligt werden hann, bis zur Syrupconsistenz ein, so erhält man concentrisch faserige, dem Wavellit sehr ähnlich sehende Krystallmassen, die, in kochendem absolutem Alkohol gelöst, sich beim Erkalten als ein Krystallgewebe abscheiden. Auf ein Filter gebracht und mit Aether zur Entfernung der freien Milchsäure sorgfältig abgewaschen, zeigt sich das Salz als ein zart anzufüllendes, in der Wärme stark glänzendes, vollkommen luflbeständiges Krystallaggregat. Aus dem Verhalten, dafs durch Hinzufügen einer äquivalenten Menge Milchsäure zum neutralen milchsauren Kalk, zuersl wieder eine Portion desselben herauskrystallisirt, möchte man folgern können, dafs ein Ueberschufs von Milchsäure zur Bildung des sauren Salzes exforderlich, und es ist defshalb wohl vortheilhafter, von vorn herein dieser Bedingung durch Zusatz einer gröfseren Quantität Säurc zu entsprechen. 
Analyse : Sie wurde mit bei $80^{\circ}$ getrocknetem Salz angestellt.

I. Verbrennung : Es wurde sich dazu des chromsauren Bleioxyds bedient, die Mischung kalt vorgenommen und nicht ausgepumpt. 0,179 Grm. Substanz lieferten 0,094 Grm. Wasser und 0,2375 Grm. Kohlensäure.

Kalkbestimmung : Auf trockenem Weg mit Schwefelsäure ausgeführt. 0,4125 Grm. Subslanz gaben 0,1405 Grm. schwefelsauren Kalk $=0,0578$ Kalkerde.

II. Kalkbestimmung : Wie bei I. vorgenommen, 0,1645 Grm. luftrockene $=0,1504$ bei $80^{\circ}$ behandelter Substanz lieferten 0,048 Grm. schwefelsaurer Kalk $=0,0198$ Kalkerde.

Die Resultate führen zu der Formel : $(\mathrm{Ca}=20)$ :

$$
\mathrm{CaO}, \mathrm{C}_{6} \mathrm{H}_{3} \mathrm{O}_{5}+\mathrm{HO}, \mathrm{C}_{6} \mathrm{H}_{5} \mathrm{O}_{5} \text {, }
$$

welche verlangt :

\begin{tabular}{lrrc} 
& & \multicolumn{2}{c}{ gefunden } \\
Wasserstoff & 5,53 & 5,81 & II. \\
Kolilenstoff & 36,18 & 36,20 & $"$ \\
Kalkerde & 14,07 & 14,01 & 13,17 \\
Sauerstoff & 44,22 & 43,98 & "
\end{tabular}

Auf die Analyse II. kann wegen der geringen Menge angewandter Substanz kein grofser Werth gelegt werden und sio ist melır als eine oberflächliche Controle anzusehen.

Wasserbestimmung : Vom lufttrocknen Zustand auf $80^{\circ}$ erhitzt, verloren 0,6705 Grm. Substanz 0,059 Grm. Wasser $=8,80$ pC, welcher Verlust 2 Aequivalenten entspricht, welche $8,26 \mathrm{pC}$. verlangen.

Das lufttrockene Salz hälte demnach die Formel :

$$
\left(\mathrm{CaO}, \mathrm{C}_{6} \mathrm{H}_{5} \mathrm{O}_{5}+\mathrm{HO}, \mathrm{C}_{6} \mathrm{H}_{5} \mathrm{O}_{5}\right)+2 \mathrm{HO} \text {. }
$$

Wurde das Salz über $80^{\circ}$ erhitzl, so sinkt es schwach zusammen, das Luftbad roch empyreumatisch und die Zerselzung 
gab sich aufserdem in einem speciellen Fall, wo die Temperatur bis $90^{\circ}$ gesteigert worden war, durch eine Gewichlsabnahme von $0,4 \mathrm{pC}$. zu erkennen.

Auf die Existenz dieser sauren Salze glauben wir die zweibasische Nalur der Milchsäure begründen zu können, welche Annahme um so mehr gerechtfertigt erscheinen dürfte, da sich hierdurch die Bildung der Bultersäure aus der Milchsäure, bei welcher man früher eine Verdoppelung des Milchsïureatoms annehmen mufste, leichl, und unseren Begriffen und Anschauungsweisen zugänglicher, erklären lälst. Die Formel für die Milchsäure würde demnach die Gestalt :

$$
\mathrm{C}_{12} \mathrm{H}_{10} \mathrm{O}_{10}+2 \mathrm{HO}
$$

anzunehmen haben und in den neutralen Salzen beide, in den sauren 1 Aeq. Wasser durch Metalloxyd substituirt seyn.

Ueber die Resultate eines weiteren Studiums der Milchsäure, namentlich über ihr Verhalten bei höherer Temperatur und die aus den dabei auttretenden Zersetzungsproducten hervorgehenden Verbindungen, behalten wir uns einen Bericht auf spätere Zeil vor.

\section{Ueber Zinnsalzfabrication;}

von C. Nïllner.

Je mehr die wissenschafliche Sonne das Gebiet der Naturwissenschaften beleuchtet und der Mensch dadurch sich selbst und Alles, was ihn ungiebt, näher kcnnen lernt, desto mehr erkennt man, wie selbst der scheinbar geringfügigste Gegensland dem menschlichen Geiste ein grolses Feld der Forschung er- 